Supporting Information

\title{
High-Safety and High-Voltage Lithium Metal \\ Batteries Enabled by Nonflammable Ether-Based Electrolyte with Phosphazene as a Cosolvent
}

Yuan Lia , Yongling An ${ }^{\mathrm{a}}$, Yuan Tian ${ }^{\mathrm{a}}$, Chuanliang Wei ${ }^{\mathrm{a}}$, Shenglin Xiong ${ }^{\mathrm{b}}$, Jinkui

Feng, ${ }^{\mathrm{a}}$

a.SDU \& Rice Joint Center for Carbon Nanomaterials, Key Laboratory for LiquidSolid Structural Evolution \& Processing of Materials (Ministry of Education), School of Materials Science and Engineering, Shandong University, Jinan 250061, P. R. China.

b. School of Chemistry and Chemical Engineering, Shandong University, Jinan 250100, P. R. China.

Corresponding Author : Jinkui Feng

Email : jinkui@sdu.edu.cn 
Table S1. Physical properties of DME and HFPN.

\begin{tabular}{|c|c|c|c|}
\hline Compound & $\begin{array}{c}\text { Melting point } \\
\left({ }^{\circ} \mathrm{C}\right)\end{array}$ & $\begin{array}{c}\text { Boiling point } \\
\left({ }^{\circ} \mathrm{C}\right)\end{array}$ & $\begin{array}{c}\text { Flash point } \\
\left({ }^{\circ} \mathrm{C}\right)\end{array}$ \\
\hline DME & -58 & 84 & 0 \\
\hline HFPN & $25-30$ & 50.9 & $/$ \\
\hline
\end{tabular}


(a)

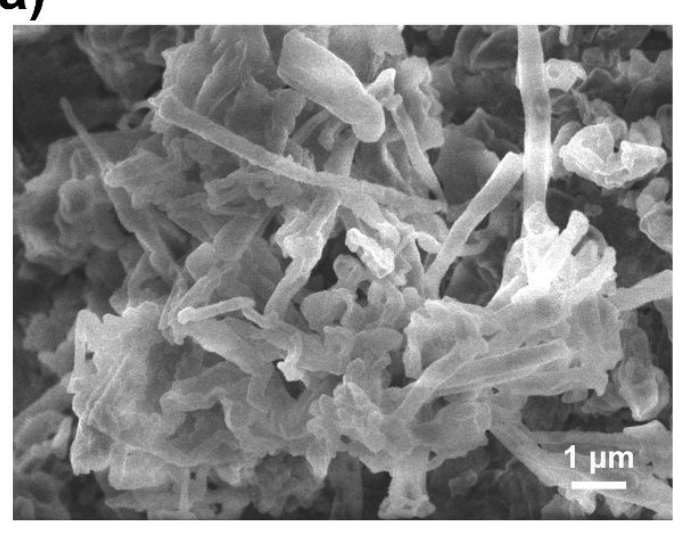

(b)

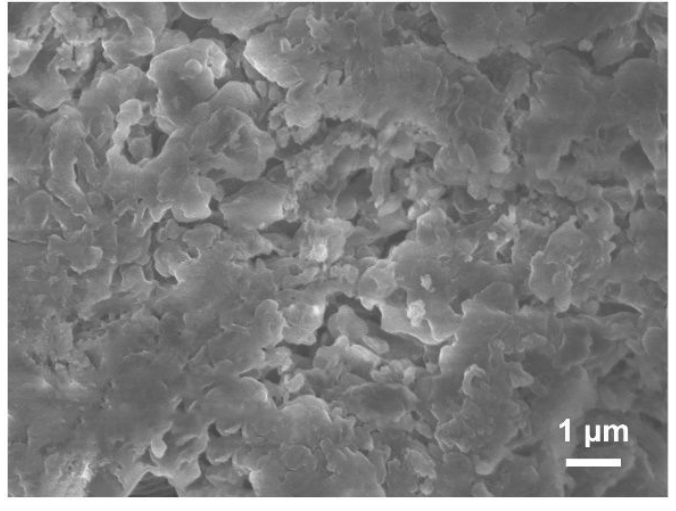

Fig. S1. The SEM images of Li mental from Li symmetric cells cycled in (a) $1 \mathrm{M}$ LiTFSI/DME and (b) 1 M LiTFSI/DME-HFPN (4:1) electrolyte. 